\title{
Correction to: Complete Factorization of the $2 m$-Band Paraunitary Polyphase Matrix with Multiple Centers of Symmetry
}

\author{
Guoqiu Wang ${ }^{1} \cdot$ Yong Chen ${ }^{1,2}$ (D) Dingxun $\mathrm{Yi}^{1}$
}

Published online: 30 October 2019

๑) Springer Science+Business Media, LLC, part of Springer Nature 2019

\section{Correction to: Circuits, Systems, and Signal Processing https://doi.org/10.1007/s00034-019-01273-0}

The original version of the article unfortunately contained an error in article title. The corrected title of the article is 'Complete Factorization of the $2 m$-Band Paraunitary Polyphase Matrix with Multiple Centers of Symmetry'.

This has been corrected with this erratum.

Publisher's Note Springer Nature remains neutral with regard to jurisdictional claims in published maps and institutional affiliations.

The original article can be found online at https://doi.org/10.1007/s00034-019-01273-0.

$凶 \quad$ Yong Chen

chenyong@ahnu.edu.cn

Guoqiu Wang

gqwang1028@sina.com

Dingxun Yi

chnmryi@foxmail.com

1 Key Laboratory of Computing and Stochastic Mathematics (Ministry of Education), School of Mathematics and Statistics, Hunan Normal University, Changsha 410081, China

2 School of Mathematics and Statistics, Anhui Normal University, Wuhu 241002, China 